\title{
New Business Models for Power Grid Enterprises in the Context of Urban Energy Internet
}

\author{
Jinyue Dou, a , Zhuhan Long ${ }^{1}$, Shiyu Meng ${ }^{1}$, Ming Zeng ${ }^{1}$, Chenjun Sun ${ }^{2}$ \\ ${ }^{1}$ School of Electrical and Electronic Engineering, North China Electric Power University, Beijing \\ 102206, China \\ ${ }^{2}$ State Grid Hebei Electric Power Company, Heibei 050000, China \\ a719086129@qq.com
}

\begin{abstract}
Keywords: Urban Energy Internet, Energy Trading Mechanisms, Distributed Energy, Micro-gird, DSM,
\end{abstract} Information Service System.

\begin{abstract}
This paper analyzes the concept and basic properties of urban energy Internet. In combination with the characteristics of energy trading mechanisms in urban energy Internet, the practical business models for power grid enterprises are proposed, which including development and investment of distributed energy, construction and operation of micro-grid, demand-side management services and construction of information service system. On the basis of analyzing the impact of urban energy internet development on power grid enterprises, the measures and suggestions are proposed with a view to providing reference for power grid enterprises.
\end{abstract}

\section{New business models in the Context of urban energy internet}

With the intensification of global climate change and gradual depletion of traditional energy sources, shifts including low carbonization, high efficiency and intellectualization has occurred in global energy systems and especially in urban energy system. As electric power is the important secondary energy resource in energy system and power systems are key hubs to promotes harmonious utilization of fossil energy and renewable energy, an urban energy Internet based on power system has the following function: drive the revolution of energy resource, achieve energy resource allocation in a wider range and promote transformation and upgrading of urban energy to be clean, electrification, intellectualization and networked.

The urban energy Internet is an electric-centered platform where interconnection, comprehensive use, optimization and share of various energy sources can be achieved. The platform has the basic properties which are multi-energy complement each other horizontally, generation-grid-load-storage coordinate vertically. The urban energy Internet also embodies the Internet characteristics including openness, interconnection, reciprocity and sharing. In urban energy Internet, the characteristics of energy trading mechanisms can be summarized from the following seven aspects: diversification of transaction subjects, diversification of trading commodities, diversification of trading decisions, transparency of transaction information, instant of transaction time, marketization of transaction management and hierarchy of transaction constraint. In the future, with the constant development of urban energy internet, the relations among transaction subjects will be more and more complex, and the change of information will accelerate. The business model of urban energy Internet will also develop from centralized comprehensive balance to partial micro-balance which based on decentralized decision and Pareto optimum.

New operating models and profit margins will emerge in power supply, transmission network, clients, Internet system and other modules in urban energy Internet. The implementable business models including development and investment of distributed energy, construction and operation of micro-grid, demand-side management services and construction of information service system.

\subsection{Development and investment of distributed energy}

Since the distributed energy will be one of the important sources of electrical energy in urban energy Internet, development and investment of distributed energy is a critical business model of urban 
energy Internet. Energy service providers invest in the construction of distributed photovoltaic power generator, small-sized fans, fuel cell power plants, energy storage equipment and other distributed energy. The direct benefits for energy service providers are the electricity charges. If add heating technology and refrigeration technology to the energy Internet such as CCHP system based on natural gas, the energy service providers can also charge users for heating and cooling services.

\subsection{Construction and operation of micro-grid}

As an important component of urban energy Internet, micro-grid can be regarded as a small regional energy Internet, which is a cushion between the distributed energy and the power grid. Energy service providers become micro-grid operators by helping users construct and operate multiple energy micro-grid, then charge users for construction and operation services. There are two methods to calculate the charges of micro-grid construction and operation services: The first approach is approving the costs and profits of micro-grid construction and operation, just like the assessment of transmission and distribution price. The other approach is allowing the energy service providers to gain profit by sharing the cost savings, sale proceeds and subsidies with micro-grid users. The cost savings is collected from power self-generation and self-usage, the sale proceeds is derived by selling surplus electricity On-grid and the subsidies are provided by government.

\subsection{Demand-side Management services}

In the urban energy Internet, both supply-side and demand-side of energy are characterized by random fluctuation. In order to adapt to new situation, the energy service providers provide value-added services for demand-side management. Demand-side management can effectively reduce random fluctuation of demand-side, help users achieve energy saving and consumption reduction, and take the initiative to adapt to the supply side output changes. There are a great variety of value-added services of demand-side management, specifically including optimized power consumption scheme, energy diagnosis, energy performance contracting, self-service with mobile APP and so forth. The energy service providers grasp the user's load characteristics and electricity consuming behavior characteristics with the aid of big data analysis and cloud computing technology. As for the charge, the energy service providers can charge the users directly or share energy-saving benefits with them.

\subsection{Construction of information service system}

In the future, the ability to obtain and handle information in urban energy Internet is the key for energy service providers to profit from overall energy services. The energy information of multi energy module can be collected, analyzed and excavated by using technologies such as intelligent sensing, cloud computing, big data analysis, and block chaining. And informatization service systems should be established which including information collection center, information processing center and information feedback center. All categories of users access the system through a pervasive interface. The energy statistics can be collected by the system, and users can access to suitable energy information services customized with their demand, and overall energy utilization scheme is arranged according to optimization calculation result. The services above are pay-needed and all served by energy service providers.

\section{The impact of urban energy Internet development on Power Grid Enterprises}

In the future, the new power system will be the core and hub of urban energy Internet, and electric energy will become the link and interface for interconnection of all kinds of energy. Accordingly, power grid enterprises play important roles in the urban energy Internet, and need to act both as grid operators and energy service providers. With the large-scale development and utilization of clean energy, interconnection of multiple energy sources and improvement of marketization level, the development of urban energy Internet will have a profound impact on power grid enterprises in many aspects, such as market environment, profit model and system operation.

First, the diversification of the main competitors. In urban energy Internet, the production and supply of energy will be transformed from a single model into a diversified model. Energy providers must be capable of providing electricity, gas, oil, and many other energy sources. Traditional power 
grid enterprises, oil companies and natural gas companies will all be transformed into overall energy suppliers with multiple energy resources. And information service enterprises, energy saving service enterprises, equipment manufacturing enterprises, energy finance enterprises and other new market players who can provide value-added services will also be involved. Apparently, because of the diversification of the main competitors, power grid enterprises will face competition among multiple market players in urban energy Internet.

Second, the diversification of profit models. The development of new technologies and new markets in urban energy Internet will promote the diversified development of power grid enterprises' profit model. It will switch from a single-energy supplier to an overall energy supplier with a variety of energy resources, and the traditional model of energy selling will be transformed into a new model of services selling. Apart from traditional services, such as construction and operation of power grid and energy selling, power grid enterprises can also launch other services like distributed energy development, micro-grid construction and operation, demand-side management services and information service system construction. Besides sharing energy-saving benefits with users, power grid enterprises can charge users for energy supply, energy Internet construction and operation as well as information services. And the market competitiveness can be enhanced by service expending and service level improvement.

Third, the complication of system operation. The core connotation of urban energy Internet is large-scale utilization and sharing of renewable energy resources. But renewable energy is random, intermittent and volatility, the increasing capacity of grid-connected renewable energy power generation will lead to bilateral random fluctuations of energy supply and demand, especially the distributed renewable energy and electric vehicles. Thus, significant impact on the safe operation of the power grid will be caused. In addition, under the request of urban energy Internet, which is multi-source complement each other horizontally, generation-grid-load-storage coordinate vertically, the operation of system will be more complex. Power grid enterprises need to ensure economy and security of the system, at the same time, improve large-scale consumptive ability of a variety of renewable power.

\section{Measures and Suggestions}

Power grid enterprises are the backbones of the urban energy Internet construction, the urban energy Internet brings new development opportunities for power grid enterprises as well. In these circumstances, in order to take the first chance in urban energy Internet market, power grid enterprises should develop new business models, broaden profit channels and enhance market competitiveness. The suggestion is implement the 4321 strategies, which are four networks combined, three kinds of technologies integration, two platforms construction and one scheme provision.

First, four networks combined, which is Internet plus power grid plus telecommunication network plus broadcast and television network. Many years ago, Power grid enterprises has planned to integrate the four networks through the implementation of smart grid projects like power fiber optic. At present, China's informatization construction and information system construction are becoming increasingly perfect. The four networks combined is expected to become an important support for the urban energy Internet. Only the power grid can support the historic mission of integrating the four networks in the future.

Second, three kinds of technologies integration, which including energy storage technology, smart home technology and comprehensive regulation technology of demand-side resources. Relying on the combination of the above three technologies, power grid enterprises can achieve the following 2 functions: First, renewable energy utilization can be promoted by deploying storage resources of power grid enterprises. Second, data acquisition and function control of each node type power unit are carried out to fully invoke the user's demand-side resources, so as to realize load dispatch.

Third, two platforms construction, which including multi-function trading platform and active distribution network platform. On the one hand, the multi-functional trading platform can realize the 
diversification of transaction functions, users can not only buy electricity on the platform, but also customize the power services and even energy services according to their own needs. On the other hand, active distribution network platform can realize automatic flexible control of user load and power flow through a variety of active deployment control technology, thus to reduce the adverse effects of grid-connected renewable energy and user demands diversification on the operation of power grid.

Fourth, one scheme provision, which is overall energy solution. Power grid enterprises should not limit themselves to the sale of electricity and other ancillary services. Instead, overall energy services packages, including water, electricity, heat, cold, gas should be provided to users on the basis of overall energy analysis. Overall energy solution is the main business model of energy Internet market. Actually, whether power generation companies or power grid enterprises or energy selling companies with social capital have the conditions for implementation, but it is more convenient for power grid enterprises to carry out the business, because of its special industrial advantages.

\section{Acknowledgments}

The paper is supported by the Science and Technology Program of SGCC (Implementation plan and support system of constructing power service platform by SGCC under the new policy environment).

\section{References}

[1] Shiping LIN, Bin Chen. Distributed energy industry development opportunities and business model innovation. Journal of Shenyang Institute of Engineering (Natural Science). 2012(08)

[2] Juhua Hong, Junyong Liu, Yue Xiang, et al. Preliminary understanding and research prospect of urban energy internet. Electric Power Automation Equipment. 2017, 37(06)

[3] Ming ZENG, Geng WU, Haojing WANG, et al. Regulation strategies of demand response considering user satisfaction under smart power background. Power System Technology. 2016, 40(10)

[4] Qixin CHEN, Dunnan LIU, Jin LIN, et al. Business models and market mechanisms of energy internet. Power System Technology. 2015, 39(11)

[5] Ming ZENG, Hongzhi Liu, Song Xue. Commercial Investment Model and Implementation Path of Distributed Energy Resources. East China Electric Power. 2012, 40(3)

[6] Junhong Wu, Min Cui, Weiqing Sun, Yiming Tan. Study for Commercial Mode of Micro Energy Network in the Market Environment. Process Automation Instrumentation. 2017, 18(1) 